\title{
ANGPTL4 variants E40K and T266M are associated with lower fasting triglyceride levels in Non-Hispanic White Americans from the Look AHEAD Clinical Trial
}

\author{
Melissa C Smart-Halajko ${ }^{*}$, Alyson Kelley-Hedgepeth², Maria Claudia Montefusco², Jackie A Cooper ${ }^{1}$, Alan Kopin², \\ Jeanne M McCaffery ${ }^{3}$, Ashok Balasubramanyam ${ }^{4}$, Henry J Pownall ${ }^{4}$, David M Nathan ${ }^{5}$, Inga Peter ${ }^{6}$, \\ Philippa J Talmud ${ }^{1}$, Gordon S Huggins ${ }^{2^{*}}$ and for the Look AHEAD Study
}

\begin{abstract}
Background: Elevated triglyceride levels are a risk factor for cardiovascular disease. Angiopoietin-like protein 4 (Angpt/4) is a metabolic factor that raises plasma triglyceride levels by inhibiting lipoprotein lipase (LPL). In nondiabetic individuals, the ANGPTL4 coding variant E4OK has been associated with lower plasma triglyceride levels while the T266M variant has been associated with more modest effects on triglyceride metabolism. The objective of this study was to determine whether ANGPTL4 E40K and T266M are associated with triglyceride levels in the setting of obesity and T2D, and whether modification of triglyceride levels by these genetic variants is altered by a lifestyle intervention designed to treat T2D.
\end{abstract}

Methods: The association of ANGPTL4 E4OK and T266M with fasting triglyceride levels was investigated in 2,601 participants from the Look AHEAD Clinical Trial, all of whom had T2D and were at least overweight. Further, we tested for an interaction between genotype and treatment effects on triglyceride levels.

Results: Among non-Hispanic White Look AHEAD participants, ANGPTL4 K40 carriers had mean triglyceride levels of $1.61 \pm 0.62 \mathrm{mmol} / \mathrm{L}, 0.33 \mathrm{mmol} / \mathrm{L}$ lower than E40 homozygotes $(p=0.001)$. Individuals homozygous for the minor M266 allele (MAF 30\%) had triglyceride levels of $1.75 \pm 0.58 \mathrm{mmol} / \mathrm{L}, 0.24 \mathrm{mmol} / \mathrm{L}$ lower than T266 homozygotes $(p=$ 0.002). The association of the M266 with triglycerides remained significant even after removing K40 carriers from the analysis $(p=0.002)$. There was no interaction between the weight loss intervention and genotype on triglyceride levels. Conclusions: This is the first study to demonstrate that the ANGPTL4 E40K and T266M variants are associated with lower triglyceride levels in the setting of T2D. In addition, our findings demonstrate that ANGPTL4 genotype status does not alter triglyceride response to a lifestyle intervention in the Look AHEAD study.

\section{Background}

Studies in large Western [1] and Asian [2] population cohorts have demonstrated an independent association between elevated triglyceride levels and cardiovascular disease (CVD) risk. Triglyceride levels may become elevated through independent effects caused by the metabolic syndrome and type 2 diabetes (T2D), both

\footnotetext{
* Correspondence: m.smart-halajko@qmul.ac.uk;

ghuggins@tuftsmedicalcenter.org

'Division of Cardiovascular Genetics, British Heart Foundation Laboratories, Department of Medicine, Royal Free and UCL Medical School, London, UK ${ }^{2}$ MCRI Center for Translational Genomics, Molecular Cardiology Research

Institute, Tufts Medical Center, Boston, MA, USA

Full list of author information is available at the end of the article
}

well-established risk factors for CVD [3]. Furthermore, lifestyle changes can significantly reduce triglyceride levels [4] and may moderate the risk of CVD [5].

Lipoprotein lipase (LPL) regulates triglyceride levels by hydrolyzing the triglyceride component of circulating lipoproteins [6,7]. At least some of the effects of T2D on triglycerides are mediated by LPL, whose expression and activity is influenced by insulin [6,7]. The angiopoietin-like protein 4 (Angptl4) peptide, which is primarily expressed in the liver and white adipose tissue [8], is another well established regulator of LPL activity and triglyceride levels. In vitro studies confirm that Angptl4, acting as an oligomer, inhibits enzymatic

\section{Biomed Central}


hydrolysis of triglycerides by preventing LPL dimerization [9]. ANGPTL4 has two common coding SNPs: E40K and T266M. The E40K substitution prevents Angptl4 oligomer formation, which leads to reduced Angptl4 mediated inhibition of LPL activity [10]. To date, results in over 30,000 individuals from non-diabetic [11] and population-based [12] studies have confirmed that the E40K loss-of-function variant is associated with significantly lower triglyceride levels $[11,12]$. In contrast, the ANGPTL4 T266M cSNP, which is more prevalent than $\mathrm{E} 40 \mathrm{~K}$, has been shown to have a smaller effect on triglyceride levels in non-diabetic populations [12].

Given the importance of triglycerides and CVD risk in the context of T2D we sought to determine whether the ANGPTL4 E40K and T266M polymorphisms are associated with triglyceride levels in well characterized patients with T2D participating in the Look AHEAD study. Second, we asked whether the ANGPTL4 variants modified the triglyceride response to an intensive lifestyle intervention designed to treat $\mathrm{T} 2 \mathrm{D}$ that was randomly assigned to Look AHEAD participants. Finding an association of ANGPTL4 variants with triglyceride levels in T2D, particularly if modifiable by a lifestyle intervention, would have important implications for personalized approaches to the treatment of T2D and cardiovascular disease.

\section{Methods}

\section{Look AHEAD (Action for Health in Diabetes)}

Look AHEAD is a multicenter clinical trial examining whether an intensive lifestyle intervention (ILI) aimed at weight loss and increased activity will reduce cardiovascular disease in T2D compared with diabetes support and education (DSE). The Look AHEAD multi-ethnic cohort is comprised of 5,145 male and female participants who have T2D, aged 45-76 years, and with a body mass index (BMI) $\geq 25 \mathrm{~kg} / \mathrm{m}^{2}$. Included in our study are samples from Look AHEAD participants who self-identified their race and ethnicity as non-Hispanic White, African American or Hispanic. The design, baseline characteristics, and 1-year interim results have been described in detail $[4,13,14]$. This manuscript is based on a subset of the baseline data set from participants who provided consent for genetic studies and were enrolled from Look AHEAD sites that participated in ancillary studies (see Acknowledgement). 2,601 participants for whom DNA was available for these analyses, were genotyped for ANGPTL4 T266M (rs1044250, 6959 $\mathrm{C}>\mathrm{T}$ ) and E40K (rs116843064, $118 \mathrm{G}>\mathrm{A}$ ) cSNPs using TaqMan technology (Applied Biosciences). All participants provided written informed consent for DNA collection and genetic studies as part of Look AHEAD. The Tufts Medical Center Institutional Review Board approved the study.

\section{Statistical Methods}

Statistical analyses were performed using Intercooled Stata 10.2 for Windows (StataCorp LP, Texas, USA). A $\chi^{2}$ test compared whether the observed frequencies conformed to Hardy-Weinberg equilibrium (HWE). A general additive model of inheritance, or dominant model in the case of $\mathrm{E} 40 \mathrm{~K}$, was used to assess the association between genotype and clinical endpoints. All clinical data were log transformed to approximate a normal distribution before analysis. Multivariate linear regressions were used for baseline association analyses, controlling for known and significant confounders including: age, gender, study site, BMI, smoking, statins, diuretics, diabetes drugs, insulin, other lipid drugs, alcohol, menopause, and hormone replacement therapy (HRT) use. Using a dominant model there was $80 \%$ power to detect a $0.08 \mathrm{mmol} / \mathrm{L}$ difference in triglycerides between $\mathrm{E} 40 \mathrm{~K}$ allele carriers and non-carriers at baseline. Using an additive model there was $80 \%$ power to detect a difference at baseline of $0.02 \mathrm{mmol} / \mathrm{L}$ in triglyceride levels per T266M allele. Both power calculations are based on a 2 -sided test at $5 \%$ significance level.

Multivariate linear regression was also utilized to determine interaction of DSE and ILI with E40K and T266M genotype. Additional association analyses performed at the 1-year follow-up time point were adjusted for age, gender, study site and the baseline measure of the dependent variable. $P$ values $<0.05$ were considered significant. Linkage disequilibrium (LD) between sites was estimated using Haploview (http://www.broad.mit. edu/mpg/haploview) version 3.0.

\section{Results \\ ANGPTL4: effects on plasma Triglyceride and HDL levels in Look AHEAD}

Baseline characteristics of the Look AHEAD study participants included in these analyses, separated by ethnic groups, are shown in Table 1 . Of the 2,601 study participants, 1,424 are taking lipid lowering medication. ANGPTL4 genotype frequences are shown in Table 2. All genotype distributions were in HWE. No LD was observed between E40K and T266M in non-Hispanic White Americans $\left(D^{\prime}=1.00\right.$ and $\left.r^{2}=0.05\right)$. The MAF for the E40K and T266M variants did not differ significantly between non-Hispanic Whites and Hispanics. The MAF of the E40K SNP in African Americans by comparison was very low (MAF 0.001).

After adjustment for covariates, the E40K variant was significantly associated with baseline plasma triglyceride levels in non-Hispanic White Look AHEAD participants (Table 3). Individuals who were $\mathrm{K} 40$ carriers had mean \pm SD triglyceride levels of $1.61 \pm 0.62 \mathrm{mmol} / \mathrm{L}, 0.33$ $\mathrm{mmol} / \mathrm{L}$ lower than E40 homozygotes $(\mathrm{p}=0.001)$. A significant association of the T266M and triglyceride levels 
Table 1 Baseline Data in Look AHEAD Genetic cohort by ethnic group

\begin{tabular}{|c|c|c|c|c|c|c|c|c|c|c|}
\hline \multirow[t]{2}{*}{ Variable } & \multicolumn{3}{|c|}{ Non-Hispanic white Americans } & \multicolumn{3}{|c|}{ African American } & \multicolumn{3}{|c|}{ Hispanics } & \multirow[t]{2}{*}{$P$ value* } \\
\hline & $\mathbf{n}$ & Mean & $95 \% \mathrm{Cl}$ & $\mathbf{N}$ & Mean & $95 \% \mathrm{Cl}$ & $\mathrm{n}$ & Mean & $95 \% \mathrm{Cl}$ & \\
\hline Female (\%) & 2023 & 50.2 & - & 436 & 76.6 & - & 142 & 64.8 & - & \\
\hline Insulin Use (\%) & 2023 & 17.0 & - & 436 & 22.9 & - & 142 & 19.7 & - & \\
\hline Statin Use (\%) & 2023 & 50.1 & - & 436 & 37.6 & - & 142 & 38.0 & - & \\
\hline Metabolic Syndrome (\%) & 2023 & 95.4 & - & 436 & 76.6 & - & 142 & 64.8 & - & \\
\hline Hypertension (\%) & 2023 & 84.9 & - & 436 & 89.5 & - & 142 & 81.0 & - & \\
\hline Age (years) & 2023 & 59.47 & $(59.17,59.77)$ & 436 & 58.40 & $(57.97,58.83)$ & 142 & 57.32 & $(56.46,58.19)$ & $<0.001$ \\
\hline $\mathrm{HbA1c}(\%)$ & 2023 & 7.17 & $(7.12,7.21)$ & 436 & 7.34 & $(7.27,7.41)$ & 142 & 7.52 & $(7.38,7.66)$ & $<0.001$ \\
\hline Weight (lbs) & 2023 & 223.85 & $(222.28,255.44)$ & 436 & 220.83 & $(218.54,223.14)$ & 142 & 217.85 & $(213.36,222.43)$ & 0.021 \\
\hline BMI (kg/m2) & 2023 & 35.88 & $(35.65,36.11)$ & 436 & 35.93 & $(35.58,36.29)$ & 142 & 35.99 & $(35.29,36.70)$ & 0.790 \\
\hline Waist circumference $(\mathrm{cm})$ & 2020 & 114.98 & $(114.42,115.55)$ & 436 & 113.17 & $(112.34,114.00)$ & 142 & 111.38 & $(109.77,113.01)$ & $<0.001$ \\
\hline Triglyceride (mmol/L) & 2023 & 1.87 & $(1.82,019)$ & 436 & 1.57 & $(1.52,1.62)$ & 142 & 1.32 & $(1.23,1.41)$ & $<0.001$ \\
\hline LDL-cholesterol (mmol/L) & 1975 & 2.77 & $(2.74,2.80)$ & 427 & 2.80 & $(2.75,2.86)$ & 138 & 2.84 & $(2.73,2.94)$ & 0.269 \\
\hline HDL-cholesterol (mmol/L) & 1975 & 1.06 & $(1.05,1.07)$ & 427 & 1.11 & $(1.09,1.13)$ & 138 & 1.16 & $(1.13,1.20)$ & $<0.001$ \\
\hline Cholesterol (mmol/L) & 1975 & 4.85 & $(4.81,4.89)$ & 427 & 4.81 & $(4.75,4.87)$ & 138 & 4.77 & $(4.66,4.89)$ & 0.242 \\
\hline Fasting Glucose (mmol/L) & 1975 & 8.32 & $(8.22,8.42)$ & 427 & 8.09 & $(7.95,8.24)$ & 138 & 7.88 & $(7.60,8.16)$ & 0.007 \\
\hline $\mathrm{SBP}(\mathrm{mm} / \mathrm{Hg})$ & 1993 & 128.82 & $(128.06,129.58)$ & 432 & 129.52 & $(128.39,130.66)$ & 140 & 130.23 & $(127.98,132.52)$ & 0.268 \\
\hline $\mathrm{DBP}(\mathrm{mm} / \mathrm{Hg})$ & 1993 & 69.41 & $(69.03,69.80)$ & 432 & 70.98 & $(70.4,71.57)$ & 140 & 72.59 & $(71.41,73.79)$ & $<0.001$ \\
\hline
\end{tabular}

Data presented is mean (95\% confidence intervals), adjusted for age and gender; ${ }^{*}$ overall comparison between the three ethnic groups after adjustment for gender.

was also observed (Table 4). Individuals homozygous for the M266 allele had triglyceride levels of $1.75 \pm 0.58$ $\mathrm{mmol} / \mathrm{L}, 0.24 \mathrm{mmol} / \mathrm{L}$ lower than T266 homozygotes (p $=0.002$ ). The association of E40K and T266M with triglyceride levels remained significant in those individuals not taking a lipid lowering medication (Tables 3 and 4, respectively). The association of $\mathrm{E} 40 \mathrm{~K}$ with triglyceride levels was also significant in subjects taking lipid lowering drugs, while the triglyceride association with T266M was not found in the setting of lipid lowering therapy (data not shown).

We examined whether the association of T266M with triglyceride levels merely reflected the presence of E40K or whether the effect was also observed independently. When the K40 carriers were excluded, the association of T266M with triglycerides remained significant in multivariate linear regression using an additive model of inheritance, with M266 homozygotes having $0.25 \mathrm{mmol} /$
L lower triglycerides compared to TT individuals ( $\mathrm{p}=$ 0.002) (Table 4).

Next, we analyzed participants by composite E40K and T266M genotypes. We found a significant genotype dosage effect in which the addition of K40 to M266 was associated with lower triglyceride levels suggesting an additive effect in the Look AHEAD cohort (Figure 1). Homozygous M266 carriers that were also heterozygous K40 carriers had the lowest triglyceride levels.

Secondary analyses of traits related to the metabolic syndrome detected a significant association of E40K with systolic blood pressure $(4.24 \mathrm{~mm} / \mathrm{Hg}$ lower in $\mathrm{K} 40$ carriers; $\mathrm{p}=0.031$ ) (Table 3 ) and a modest association with waist circumference $(\mathrm{p}=0.043)$. Only triglyceride levels showed significant differences by T266M genotype (Table 4).

We were unable to test an association of E40K and triglycerides in African American and Hispanic Look

Table 2 Look AHEAD genotype frequencies of ANGPTL4 E40K and T266M by ethnic group

\begin{tabular}{|c|c|c|c|c|c|c|c|c|c|c|c|c|c|}
\hline \multirow[t]{2}{*}{ ANGPTL4 variant } & \multirow[t]{2}{*}{ Genotype } & \multicolumn{3}{|c|}{ Non-Hispanic White Americans } & \multicolumn{3}{|c|}{ African American } & \multicolumn{3}{|c|}{ Hispanic } & \multicolumn{3}{|c|}{$P$ value } \\
\hline & & $\mathbf{n}$ & $\%$ & MAF & $\mathbf{n}$ & $\%$ & MAF & $\mathbf{n}$ & $\%$ & MAF & p1 & p2 & p3 \\
\hline E40K & $118 \mathrm{G}>\mathrm{A}$ & & & & & & & & & & & & \\
\hline $\mathrm{EE}$ & $\mathrm{GG}$ & 1868 & 95.8 & & 418 & 99.8 & & 129 & 95.6 & & & & \\
\hline EK/KK & GA/AA & $82 / 0$ & 4.2 & 0.021 & $1 / 0$ & 0.2 & 0.001 & $5 / 1$ & 4.4 & 0.027 & $<0.001$ & 0.551 & $<0.001$ \\
\hline T266M & rs1044250 & & & & & & & & & & & & \\
\hline$\pi$ & $\mathrm{CC}$ & 961 & 48.1 & & 242 & 56.0 & & 63 & 45.0 & & & & \\
\hline $\mathrm{TM}$ & $\mathrm{CT}$ & 845 & 42.2 & & 164 & 34.0 & & 61 & 43.6 & & & & \\
\hline MM & $\pi$ & 194 & 9.7 & 0.31 & 26 & 6.0 & 0.25 & 16 & 11.4 & 0.33 & $<0.001$ & 0.403 & 0.007 \\
\hline
\end{tabular}

p1; Non-Hispanic whites vs. African Americans, p2; Non-Hispanic whites vs. Hispanics, p3; African Americans vs. Hispanics. 
Table 3 Association of E40K with baseline data in Non-Hispanic White Look AHEAD participants

\begin{tabular}{|c|c|c|c|}
\hline & $\mathrm{EE}$ & EK & $P$ value \\
\hline & Mean $(95 \% \mathrm{Cl})$ & Mean $(95 \% \mathrm{Cl})$ & \\
\hline $\mathrm{n}$ males/n females & $934 / 934$ & $40 / 42$ & - \\
\hline Triglycerides (mmol/L) & $1.94(1.90,1.99)$ & $1.61(1.44,1.80)$ & 0.001 \\
\hline Cholesterol (mmol/L) & $4.86(4.82,4.90)$ & $4.88(4.69,5.08)$ & 0.889 \\
\hline LDL-cholesterol (mmol/L) & $2.77(2.73,2.80)$ & $2.87(2.70,3.04)$ & 0.237 \\
\hline HDL-cholesterol (mmol/L) & $1.05(1.04,1.06)$ & $1.10(1.05,1.16)$ & 0.081 \\
\hline BMI $\left(\mathrm{kg} / \mathrm{m}^{2}\right)$ & $35.90(35.87,35.93)$ & $35.91(35.78,36.03)$ & 0.940 \\
\hline Weight (kg) & $100.55(100.21,100.90)$ & $101.51(99.88,103.17)$ & 0.264 \\
\hline Waist Circumference $(\mathrm{cm})$ & $115.03(114.69,115.37)$ & $116.73(115.11,118.37)$ & 0.043 \\
\hline Glucose (mmol/L) & $8.38(8.28,8.49)$ & $8.02(7.56,8.51)$ & 0.154 \\
\hline $\mathrm{HbA1c}$ & $7.18(7.14,7.23)$ & $7.00(6.79,7.22)$ & 0.113 \\
\hline $\mathrm{SBP}(\mathrm{mm} / \mathrm{Hg})$ & $129.12(128.31,129.93)$ & $124.88(121.23,128.64)$ & 0.031 \\
\hline $\mathrm{DBP}(\mathrm{mm} / \mathrm{Hg})$ & $69.38(68.98,69.79)$ & $67.55(65.71,69.43)$ & 0.062 \\
\hline Triglycerides (mmol/L) on subjects not receiving lipid lowering medication & $\begin{array}{c}1.91(1.85,1.98) \\
(n=771)\end{array}$ & $\begin{array}{c}1.54(1.31,1.80) \\
(n=36)\end{array}$ & 0.007 \\
\hline
\end{tabular}

Data presented is mean (95\% confidence intervals). Lipid data and blood pressure are adjusted for age, gender, study site, BMl, smoking, statins, diuretics, diabetes drugs, insulin, other lipid drugs, alcohol, menopause, HRT use. Anthropometric data are adjusted for age, gender, study site, smoking, statins, diuretics, diabetes drugs, insulin, other lipid drugs, alcohol, menopause, HRT use. Adjusted $P$ values using a dominant model of inheritance are presented.

AHEAD participants due to the low number of genotype carriers (Additional File 1: Supplemental Tables 1 and 2).

One year follow-up data in non-Hispanic white Americans Look AHEAD participants in this genetic sub-cohort randomly assigned to DSE achieved a $1 \%$ reduction of BMI compared with an $11 \%$ reduction in the ILI group $(\mathrm{p}<0.001)$. The response to DSE and ILI in the Look AHEAD participants taking part in these genetic studies was similar to the one-year differences observed in the full cohort [4]. Triglyceride levels decreased in both randomisation groups, with subjects in the ILI group achieving 27\% lower levels compared with 9\% lower levels in the DSE group. Tests for interaction between intervention and $\mathrm{E} 40 \mathrm{~K}$ and $\mathrm{T} 266 \mathrm{M}$ status were not statistically significant ( $\mathrm{p}=0.416$ and 0.202 respectively). The absolute changes in triglyceride levels were similar between E40K and T266M genotypes (Additional File 1: Supplemental Tables 3 and 4).

\section{Discussion}

In this study, we demonstrate for the first time that ANGPTL4 E40K and T266M are associated with triglyceride levels in the setting of T2D. This finding is

Table 4 Association of T266M with baseline data in Non-Hispanic White Look AHEAD participants

\begin{tabular}{|c|c|c|c|c|}
\hline & $\begin{array}{c}\text { TT } \\
\text { Mean }(95 \% \mathrm{CI})\end{array}$ & $\begin{array}{c}\text { TM } \\
\text { Mean }(95 \% \mathrm{CI})\end{array}$ & $\begin{array}{c}\text { MM } \\
\text { Mean }(95 \% \mathrm{Cl})\end{array}$ & $P$ value \\
\hline $\mathrm{n}$ males/n females & $461 / 500$ & $428 / 417$ & $93 / 101$ & - \\
\hline Triglycerides (mmol/L) & $1.99(1.93,2.06)$ & $1.87(1.81,1.94)$ & $1.75(1.63,1.89)$ & 0.002 \\
\hline Cholesterol (mmol/L) & $4.91(4.85,4.96)$ & $4.84(4.78,4.90)$ & $4.79(4.66,4.91)$ & 0.120 \\
\hline LDL-cholesterol (mmol/L) & $2.78(2.73,2.82)$ & $2.77(2.72,2.83)$ & $2.75(2.65,2.86)$ & 0.937 \\
\hline HDL-cholesterol (mmol/L) & $1.05(1.04,1.07)$ & $1.05(1.05,1.12)$ & $1.09(1.05,1.12)$ & 0.178 \\
\hline BMI $\left(\mathrm{kg} / \mathrm{m}^{2}\right)$ & $35.94(35.90,35.97)$ & $35.89(35.85,35.93)$ & $35.97(35.89,36.05)$ & 0.101 \\
\hline Weight (lbs) & $100.71(100.22,101.19)$ & $100.31(99.80,100.83)$ & $101.10(100.03,102.18)$ & 0.331 \\
\hline Waist Circumference $(\mathrm{cm})$ & $115.08(114.61,115.55)$ & $114.91(114.40,115.41)$ & $115.77(114.72,116.82)$ & 0.346 \\
\hline Glucose (mmol/L) & $8.44(8.30,8.59)$ & $8.32(8.17,8.47)$ & $8.19(7.89,8.51)$ & 0.269 \\
\hline HbA1c & $7.22(7.16,7.29)$ & $7.13(7.02,7.20)$ & $7.08(6.95,7.23)$ & 0.067 \\
\hline $\mathrm{SBP}(\mathrm{mm} / \mathrm{Hg})$ & $129.18(128.06,130.30)$ & $128.68(127.48,129.88)$ & $126.85(124.41,129.34)$ & 0.243 \\
\hline $\mathrm{DBP}(\mathrm{mm} / \mathrm{Hg})$ & $69.45(68.89,70.01)$ & $69.15(68.55,69.76)$ & $68.43(67.20,69.68)$ & 0.327 \\
\hline $\begin{array}{l}\text { Triglyceride ( } \mathrm{mmol} / \mathrm{L}) \\
\text { Following removal of E40K Carriers }\end{array}$ & $\begin{array}{c}1.99(1.92,2.06) \\
(n=889)\end{array}$ & $\begin{array}{c}1.88(1.81,1.95) \\
(n=775)\end{array}$ & $\begin{array}{c}1.73(1.60,1.88) \\
(n=182)\end{array}$ & 0.002 \\
\hline $\begin{array}{l}\text { Triglycerides (mmol/L) } \\
\text { Subjects not taking lipid-lowering medication }\end{array}$ & $\begin{array}{c}1.95(1.86,2.05) \\
(n=416)\end{array}$ & $\begin{array}{c}1.82(1.74,1.93) \\
(n=344)\end{array}$ & $\begin{array}{c}1.66(1.48,1.85) \\
(n=75)\end{array}$ & 0.01 \\
\hline
\end{tabular}

Data presented is mean (95\% confidence intervals). Lipid data and blood pressure are adjusted for age, gender, study site, BMI, smoking, statins, diuretics, diabetes drugs, insulin, other lipid drugs, alcohol, menopause, HRT use. Anthropometric data are adjusted for age, gender, study site, smoking, statins, diuretics, diabetes drugs, insulin, other lipid drugs, alcohol, menopause, HRT use. Adjusted $P$ values using an additive model of inheritance are presented. 


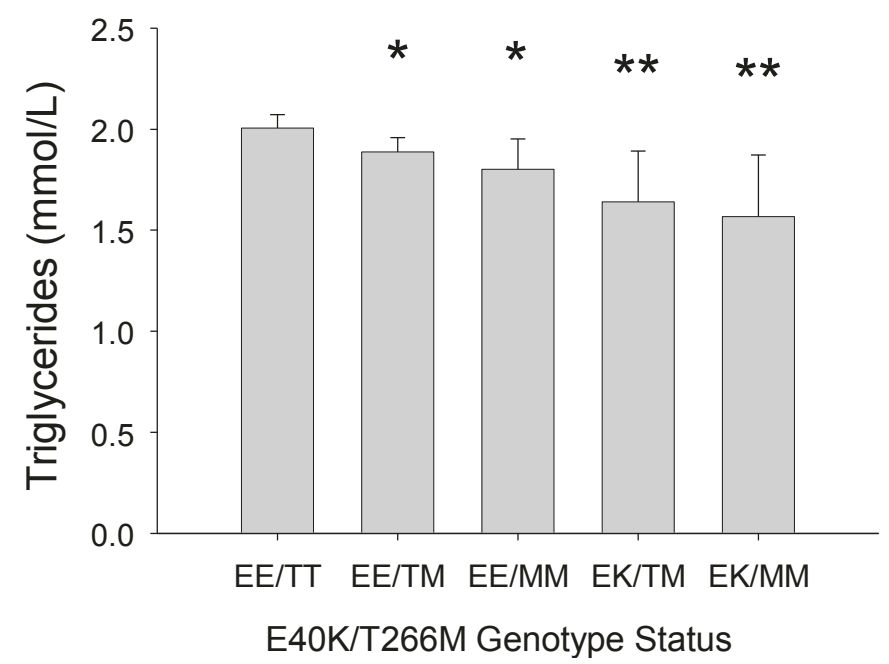

Figure 1 Mean triglyceride levels in Non-Hispanic White Americans from Look AHEAD by Composite ANGPTL4 E40K and T266M genotype. Triglyceride data are adjusted for age, gender, study site, BMI, smoking, statins, diuretics, diabetes drugs, insulin, other lipid drugs, alcohol, menopause, HRT use; $P$ value comparing mean triglycerides to the reference EE/TT composite genotype carriers; * indicates $P<0.05$ and ** indicates $P<0.01$. No Look AHEAD participant was found to carry the composite EK/T genotype.

significant because elevated triglyceride levels found in E40 homozygotes and T266 carriers may contribute to an increased risk of CVD in the setting of T2D. NonHispanic White Look AHEAD K40 carriers had 17\% lower triglyceride levels than non-K40 carriers, which is a similar effect as reported in studies in the general population $[11,12]$. We therefore conclude that the effect of the ANGPTL4 E40K polymorphism is unlikely diminished to any substantial degree by the independent effects of obesity and T2D on triglyceride levels. The lack of interaction with treatment indicates that there is no differential effect of genotypes on triglycerides depending upon randomization to ILI versus DSE. This final point demonstrates the potential role of a life-style intervention to reduce triglyceride levels conferred by genetic background [15].

We identified an association of triglyceride levels with ANGPTL4 T266M that appeared to be independent of, and potentially additive with, the E40K variant. The T266M triglyceride effect is consistent with the European Atherosclerosis Research Study II CHD offspring study which demonstrated that M266 homozygotes had enhanced triglyceride clearance following an oral fat tolerance test [12]. Our results contrast to the findings of Talmud et al [12], who reported a similar pattern of linkage disequilibrium between the two cSNPs, but found the association of T266M with triglycerides to be dependent on the K40 allele. The observation that the triglyceride-lowering effect of T266M is not lost after removal of K40 carriers in Look AHEAD suggests that the T266M cSNP may have an independent effect on triglycerides in the setting of $\mathrm{T} 2 \mathrm{D}$. The fact that the association of T266M with triglyceride levels was not observed in Look AHEAD participants receiving lipid lowering medication, but maintained on those not on medications, suggests that an important interaction between medications and T266M may exist. Alternatively, the reduced sample size in this sub-group analysis may have reduced our power to detect an association.

E40K carriers in ARIC and the Copenhagen City Heart Study had significantly higher HDL-cholesterol levels than non-carriers, while the Dallas Heart Study did not confirm this relationship [11]. While a mechanistic link between plasma triglycerides and HDL-cholesterol mediated by the cholesterol ester transfer protein is well established [16], large differences in triglycerides are typically required before a significant change in HDL-cholesterol is found. We detected a modest, albeit non-significant, elevation of HDL-cholesterol in K40 carriers. Other factors that regulate HDL-cholesterol levels (e.g. insulin resistance, obesity) may have weakened the effect of E40K.

Both the E40 (within the N-terminus) and the T266 (within the C-terminus) amino acid residues are conserved across human, mouse and rat species [17] suggesting functional importance. Formation of Angptl4 oligomers by disulphide bonds in the coiled-coil N-terminus [17] is required for inhibition of LPL activity. The E40K substitution destabilizes the protein after secretion, preventing the extracellular accumulation of oligomers and abolishing the ability of the Angptl4 protein to inhibit LPL activity [10]. By comparison, the mechanism by which $\mathrm{T} 266 \mathrm{M}$ alters the function of the $\mathrm{C}$-terminal fibrinogen domain remains undefined. 
Romeo et al [18] has demonstrated that non-synonymous mutations throughout ANGPTL4, including the fibrinogen domain, compromise the ability of Angptl4 to inhibit LPL activity.

A limitation of the study is the low number of African American and Hispanic ANGPTL4 variant carriers. Statistically this resulted in underpowered association studies which prevented the examination of E40K in African Americans. The ANGPTL4 variant frequencies for Hispanics were comparable to Non-Hispanic White Americans (0.027 and 0.021). The low total number of Hispanics (n $=137)$ and E40K carriers $(n=6)$ reduced our power to detect an association. While we included anti-diabetic medication use as a covariate in our analyses an additional limitation is that we were unable to control for the effect of specific anti-diabetic medications and doses, which may have an effect on triglyceride levels.

\section{Conclusion}

In conclusion, we demonstrate for the first time an association of the ANGPTL4 coding variants with triglyceride levels in the setting of T2D. Further, our results suggest that the triglyceride response to a lifestyle intervention is not altered by ANGPTL4 genotype status. This finding broadens our understanding of the role of Angptl4 in regulation of LPL metabolism of triglycerides. The independent association of T266M with triglycerides has broad implications because this polymorphism has a high frequency in the general population.

\section{Additional material}

\section{Additional file 1: Supplemental Analysis of ANGPTL4 E40K and} T266M Genotype Status in Look AHEAD. This additional file includes four supplemental data tables. The first two tables describe the association analysis findings of ANGPTL4 E4OK (Table S1) and T266M (Table S2) with baseline biochemical and anthropometric baseline levels in African American and Hispanic Look AHEAD participants. The remaining two tables describe the association analysis findings of ANGPTL4 E40K (Table S3) and T266M (Table S4) with absolute change in baseline biochemical and anthropometric measurements to year 1 follow-up in Non-Hispanic White Look AHEAD participants.

\begin{abstract}
Abbreviations
Angptl4: Angiopoietin-like protein 4; BMI: body mass index; Cl: confidence intervals; CVD: cardiovascular disease; DSE: diabetes support education; HWE: Hardy-Weinberg equilibrium; HDL-cholesterol: high-density lipoprotein cholesterol; HRT-Hormone replacement therapy; ILI: intensive lifestyle intervention; LD: linkage disequilibrium; LPL: lipoprotein lipase; LDLcholesterol: low-density lipoprotein cholesterol; MAF: minor allele frequency; SNP: single nucleotide polymorphism; cSNP: coding single nucleotide polymorphism; T2D: type 2 diabetes.
\end{abstract}

\section{Acknowledgements and Funding}

We gratefully acknowledge the contributions of the Look AHEAD Study Group members [4]. This study is supported by the National Institutes of Health (R01 DK072497), the British Heart Foundation (PG2005/014) and additional sources listed below. This manuscript is based on a subset of the baseline data set from participants enrolled from the Look AHEAD sites at Pennington Biomedical Research Center; Massachusetts General Hospital; University of Colorado Health Sciences Center; Baylor College of Medicine; The University of Tennessee Health Science Center, University of Tennessee; University of Minnesota; St. Luke's Roosevelt Hospital Center; University of Pennsylvania; University of Pittsburgh; and Brown University. Additional support was received from the Massachusetts General Hospital Mallinckrodt General Clinical Research Center (M01-RR-01066); the University of Colorado Health Sciences Center General Clinical Research Center (M01 RR00051) and Clinical Nutrition Research Unit (P30 DK48520); the University of Tennessee at Memphis General Clinical Research Center (M01RR00211-40); the University of Pittsburgh General Clinical Research Center (M01 RR000056 44) and NIH grant (DK 046204). Author AKH was supported by the Training Program in Cardiovascular Research (NIH, 5T32HL069770) and MCS is supported by a Unilever/BBSRC Case studentship.

\section{Author details}

'Division of Cardiovascular Genetics, British Heart Foundation Laboratories, Department of Medicine, Royal Free and UCL Medical School, London, UK. ${ }^{2}$ MCRI Center for Translational Genomics, Molecular Cardiology Research Institute, Tufts Medical Center, Boston, MA, USA. ${ }^{3}$ Weight Control and Diabetes Research Center, Department of Psychiatry and Human Behavior, The Miriam Hospital and Brown Medical School, Providence, RI, USA. ${ }^{4}$ Baylor College of Medicine, Houston, TX, USA. ${ }^{5}$ Diabetes Unit, Massachusetts General Hospital, Harvard Medical School, Boston, MA, USA. ${ }^{6}$ Department of Genetics and Genomic Sciences, Mount Sinai School of Medicine, New York, USA.

\section{Authors' contributions}

MCS participated in all aspects of this project including molecular genetic studies, association analysis and manuscript preparation; AKH and IP advised association analysis and manuscript preparation; MCM and JAC carried out molecular genetic studies; AK, JM, AB, HJP, and DMN assisted in data interpretation and edited/reviewed the manuscript; PJT proposed and advised the study and edited/reviewed the manuscript; GSH participated in all aspects of the project including study design, molecular genetic studies, statistical analysis, and manuscript preparation. All authors read and approved the final manuscript.

\section{Competing interests}

The authors declare that they have no competing interests.

Received: 2 November 2010 Accepted: 29 June 2011

Published: 29 June 2011

\section{References}

1. Sarwar N, Danesh J, Eiriksdottir G, Sigurdsson G, Wareham N, Bingham S, Boekholdt SM, Khaw KT, Gudnason V: Triglycerides and the risk of coronary heart disease: 10,158 incident cases among 262,525 participants in 29 Western prospective studies. Circulation 2007, 115(4):450-458.

2. Patel A, Barzi F, Jamrozik K, Lam TH, Ueshima H, Whitlock G, Woodward M: Serum triglycerides as a risk factor for cardiovascular diseases in the Asia-Pacific region. Circulation 2004, 110(17):2678-2686.

3. Drexel H, Aczel S, Marte T, Benzer W, Langer P, Moll W, Saely CH: Is atherosclerosis in diabetes and impaired fasting glucose driven by elevated LDL cholesterol or by decreased HDL cholesterol? Diabetes Care 2005, 28(1):101-107.

4. Pi-Sunyer X, Blackburn G, Brancati FL, Bray GA, Bright R, Clark JM, Curtis JM, Espeland MA, Foreyt JP, Graves K, et al: Reduction in weight and cardiovascular disease risk factors in individuals with type 2 diabetes: one-year results of the look AHEAD trial. Diabetes Care 2007, 30(6):1374-1383.

5. Tirosh A, Rudich A, Shochat T, Tekes-Manova D, Israeli E, Henkin Y, Kochba I, Shai I: Changes in triglyceride levels and risk for coronary heart disease in young men. Ann Intern Med 2007, 147(6):377-385.

6. Picard F, Naimi N, Richard D, Deshaies Y: Response of adipose tissue lipoprotein lipase to the cephalic phase of insulin secretion. Diabetes 1999, 48(3):452-459.

7. Pollare T, Vessby B, Lithell H: Lipoprotein lipase activity in skeletal muscle is related to insulin sensitivity. Arterioscler Thromb 1991, 11(5):1192-1203. 
8. Kersten S: Regulation of lipid metabolism via angiopoietin-like proteins. Biochem Soc Trans 2005, 33(Pt 5):1059-1062.

9. Sukonina V, Lookene A, Olivecrona T, Olivecrona G: Angiopoietin-like protein 4 converts lipoprotein lipase to inactive monomers and modulates lipase activity in adipose tissue. Proc Natl Acad Sci USA 2006 103(46):17450-17455.

10. Yin W, Romeo S, Chang S, Grishin NV, Hobbs HH, Cohen JC: Genetic variation in ANGPTL4 provides insights into protein processing and function. J Biol Chem 2009, 284(19):13213-13222.

11. Romeo S, Pennacchio LA, Fu Y, Boerwinkle E, Tybjaerg-Hansen A, Hobbs HH, Cohen JC: Population-based resequencing of ANGPTL4 uncovers variations that reduce triglycerides and increase HDL. Nat Genet 2007, 39(4):513-516.

12. Talmud PJ, Smart M, Presswood E, Cooper JA, Nicaud V, Drenos F, Palmen J, Marmot MG, Boekholdt SM, Wareham NJ, et al: ANGPTL4 E40K and T266M: effects on plasma triglyceride and HDL levels, postprandial responses, and CHD risk. Arterioscler Thromb Vasc Biol 2008, 28(12):2319-2325.

13. Bray G, Gregg E, Haffner S, Pi-Sunyer XF, WagenKnecht LE, Walkup M, Wing R: Baseline characteristics of the randomised cohort from the Look AHEAD (Action for Health in Diabetes) study. Diab Vasc Dis Res 2006, 3(3):202-215

14. Ryan DH, Espeland MA, Foster GD, Haffner SM, Hubbard VS, Johnson KC, Kahn SE, Knowler WC, Yanovski SZ: Look AHEAD (Action for Health in Diabetes): design and methods for a clinical trial of weight loss for the prevention of cardiovascular disease in type 2 diabetes. Control Clin Trials 2003, 24(5):610-628.

15. Florez JC, Jablonski KA, Bayley N, Pollin TI, de Bakker PI, Shuldiner AR, Knowler WC, Nathan DM, Altshuler D: TCF7L2 polymorphisms and progression to diabetes in the Diabetes Prevention Program. N Engl J Med 2006, 355(3):241-250.

16. Pownall HJ, Brauchi D, Kilinc C, Osmundsen $K$, Pao Q, Payton-Ross $C$, Gotto AM, Ballantyne CM: Correlation of serum triglyceride and its reduction by omega- 3 fatty acids with lipid transfer activity and the neutral lipid compositions of high-density and low-density lipoproteins. Atherosclerosis 1999, 143(2):285-297.

17. Ge H, Yang G, Yu X, Pourbahrami T, Li C: Oligomerization state-dependent hyperlipidemic effect of angiopoietin-like protein 4. J Lipid Res 2004, 45(11):2071-2079.

18. Romeo S, Yin W, Kozlitina J, Pennacchio LA, Boerwinkle E, Hobbs HH, Cohen JC: Rare loss-of-function mutations in ANGPTL family members contribute to plasma triglyceride levels in humans. J Clin Invest 2009, 119(1):70-79.

\section{Pre-publication history}

The pre-publication history for this paper can be accessed here: http://www.biomedcentral.com/1471-2350/12/89/prepub

doi:10.1186/1471-2350-12-89

Cite this article as: Smart-Halajko et al:: ANGPTL4 variants E40K and T266M are associated with lower fasting triglyceride levels in Non-Hispanic White Americans from the Look AHEAD Clinical Trial. BMC Medical Genetics 2011 12:89.

\section{Submit your next manuscript to BioMed Central and take full advantage of:}

- Convenient online submission

- Thorough peer review

- No space constraints or color figure charges

- Immediate publication on acceptance

- Inclusion in PubMed, CAS, Scopus and Google Scholar

- Research which is freely available for redistribution

Submit your manuscript at www.biomedcentral.com/submit
Biomed Central 